\title{
Neutral Lipid Storage with Acid Lipase Deficiency: a New Variant of Wolman's Disease with Features of the Senior Syndrome
}

\author{
M. PHILIPPART, ${ }^{(4)}$ P. DURAND, AND C. BORRONE \\ Mental Retardation Research Center, University of California, UCLA Los Angeles, California, USA and \\ Third Department of Pediatrics, G. Gaslini Institute, Genova-Quarto, Italy
}

\begin{abstract}
Summary
A girl presented with small stature, obesity, tapetoretinal degeneration, deafness, psychomotor regression, seizures, acanthosis nigricans, hepatomegaly, and chronic tubulointerstitial nephropathy. She died at age ten with renal insufficiency and uncontrolled seizures. Histochemistry showed lipid storage in hepatocytes, histiocytes, smooth muscles and, to a much lesser extent, kidney tubules and cortical neurons. The liver had increased cholesterol esters (5-fold) and triacylglycerols (8-fold), and decreased phospholipids $(50 \%)$. Methyllumbelliferyl-oleate, oleylcholestrol, trioleylglycerol, and tripalmitylglycerol lipase activities were markedly reduced in the liver, in the range found in Wolman's disease. In cirrhotic fatty livers these activities ranged from $7-87 \%$ of the normal mean. The patient's brain had limited neutral lipid storage and normal methyllumbelliferyl-oleate lipase. Trioleylglycerol lipase activity was $14-60 \%$ of controls; tripalmitylglycerol lipase activity 14-25\% of controls; and oleylcholestrol lipase activity 12-33\% of controls.
\end{abstract}

\section{Speculation}

Neutral lipid storage in the kidney was minimal suggesting that unidentified factors were responsible for the tubulointerstitial nephropathy. Acid lipase activity should be investigated in the Senior syndrome and other related disorders.

A number of distinct phenotypes have been associated with a neutral lipid storage disorder. Wolman's disorder is characterized by hepatosplenomegaly, malabsorption with steatorrhea, bilateral adrenal calcification, and failure to thrive. The disease occurs in infancy and is nearly always fatal before age one (7). Cholesterol ester storage disease (CESD) is a comparatively benign disease characterized by hepatomegaly, which may not be recognized until adulthood. Patients may present bilateral adrenal calcification. Cholesterol esters account for most of the stored lipid whereas there is little accumulation of triglycerides (7). A severe congenital triglyceride storage disorder (TGSD) leading to death in the neonatal period has been reported in a unique family under the name of Fatty Metamorphosis of the Viscera (2l). Other patients have been described with phenotypes similar to those of Wolman's disease but with a longer life span (36). A severe deficiency of the lysosomal acid lipase, acting on both cholesterol esters and triglycerides has been demonstrated in these different conditions $(2$, 7,20 ). In this paper we give a follow up on a unique patient with a disease characterized by generalized accumulation of neutral lipids also due to a profound deficiency of acid lipase (22).

\section{MATERIALS AND METHODS}

[carboxy- ${ }^{14} \mathrm{C}$ ]-Oleate $(54 \mathrm{mCi} / \mathrm{mmole})$, glyceryl-[carboxy ${ }^{14} \mathrm{C}$ ]trioleate $(40 \mathrm{mCi} / \mathrm{mmole})$, glyceryl-[carboxy $\left.-{ }^{14} \mathrm{C}\right]$-tripalmitate
(37), triolein, tripalmitin, cholesteryl oleate, phosphatidylserine and phosphatidylethanolamine (38) were used to prepare lipase substrates.

Thin layer chromatography of neutral lipids was conducted by sequential runs in diethylether:benzene:ethanol:acetic acid (80:100:4:0.4) and hexane:diethyl ether (94:6) on $250 \mu$ Silica Gel $G(8)$. Lipids were visualized by exposure to iodine vapor or two-dimensional scanning (39). Lipid areas were scraped and counted in Aquasol (37). Lipid extracts $(250 \mu \mathrm{g})$ from normal human serum were used as standards for lipid identification. Enzyme extracts were prepared by extracting tissues with $9 \mathrm{vol}$ umes of water in a Potter-Elvehjem fitted with a Teflon pestle.

Control livers and brains and cirrhotic livers from alcoholics were obtained from the autopsy room and kept frozen at $-20^{\circ} \mathrm{C}$ from 3 wk to 14 years. Tissues from patients with Wolman's disease included four autopsy specimens and three open liver biopsies. Tissues from the present case were obtained at autopsy. Parental consent was given for all tests and biopsies.

Triacylglycerol lipase was determined by a modification of Kaplan's procedure (15). The labeled substrate was diluted with unlabeled lipid to provide a specific activity ranging from $200-30,000 \mathrm{cpm} / \mathrm{nmole}$. The lipids (300-500 nmole) were mixed with 20-160 mg Triton X-100 and 800 nmole phosphatidylserine in $1 \mathrm{ml}$ hexane, dried under nitrogen at $40^{\circ} \mathrm{C}$ and emulsified by adding water dropwise in a Potter-Elvehjem held at $50^{\circ} \mathrm{C}$ up to a volume of $1 \mathrm{ml}$. Fresh substrate was prepared for each set of determinations. The reaction mixture included 15-130 nmole substrate, 12.5 nmole citrate-phosphate buffer ( $\mathrm{pH} 4.0)$ or 5 nmole acetate buffer ( $\mathrm{pH} 4.25$ ), and $15-400 \mu \mathrm{g}$ of extract protein in a final volume of $75-100 \mu \mathrm{l}$. The reaction was stopped and the liberated fatty acids extracted according to Kaplan (15). Incubations were carried in triplicate for 0,30 , and $60 \mathrm{~min}$. Reactions were generally linear for $2 \mathrm{~h}$. Free fatty acid recovery varied from 34-50\% when labeled oleate was substituted for labeled triacylglycerol in the reaction mixture. Pathologic specimens were always analyzed simultaneously with controls, and fatty acid recovery was monitored for each series. Alternatively, incubations were stopped by adding $3 \mathrm{ml}$ chloroform:methanol $(2: 1)$ and analyzing neutral lipids by thin layer chromatography. Under these conditions label recovery was generally about $80 \%$ although it ranged from $75-105 \%$. When labeled oleate was mixed with serum lipids, $60 \%$ was recovered with the free fatty acids, $15 \%$ each with monoacylglycerol and diacylglycerol, and 5\% each with triacylglycerol and origin, suggesting that adsorption onto other lipids was responsible for the low and often erratic recoveries. Thin layer chromatographic analysis also allowed to follow the breakdown of the labeled triglycerides. After 10 min incubation, labeled diacyl and monoacylglycerols and free fatty acids were close to the theoretical $2 / 1$. Monoacylglycerol was a minor fraction, generally less than $2 \%$ of labeled substrate, and did not increase linearly with time after $30 \mathrm{~min}$ incubation. The sum of the three labeled products equalled the decrement in labeled substrate. No evidence 
of transesterification with phospholipids was found. Compared to $600 \mathrm{~g}$ supernates, tissue homogenates generally had about onethird less acid lipase activity, but gave more reproducible results. Extracts were stable at $-18^{\circ} \mathrm{C}$ for several wk, although in one instance a cirrhotic liver extract lost $50 \%$ activity in 4 days. Patient's extracts were stable for at least $10 \mathrm{wk}$. Cholesterol esterase was determined by the procedure of Sloan and Fredrickson (31) and acid lipase by that of Aubert-Tulkens and Van Hoof (1) using 4-methylumbelliferyl (MU)-oleate. Total lipids (5), triglycerides (4), free and esterified cholesterol (18), phospholipids (28), and protein (19) were determined according to published procedures.

Extracts from acetone powders had the same MU-oleate lipase activity as the liver homogenates in one cirrhotic liver whereas it lost $85 \%$ activity in another. Thirty percent of the acetone powder MU-oleate lipase activity was butanol soluble and 70\% was recovered in the butanol insoluble pellet. Tripalmitylglycerol and oleylcholesterol lipase retained $10-20 \%$ activity in butanol extracts from acetone powders, and none was recovered in the insoluble pellets. This suggested that endogenous lipids did not compete with or contribute to the MU-oleate lipase activity whereas they were essential to the activities against exogenous lipid substrates and could not be replaced by the phosphatidyl serine or nonionic detergents present in the substrate mixture.

Case report. The detailed clinical history has been previously reported (3). The parents were doubly consanguineous. This obese girl (Fig. 1) had a height below the third percentile, tapetoretinal degeneration with decreased vision, deafness, progressive psychomotor deterioration, seizures, acanthosis nigricans, hepatomegaly, and chronic tubulointerstitial nephropathy.

She developed painful hepatomegaly, thrombocytopenia, marked jaundice, depigmentation and partial loss of hair. She expired at 10 years and 3 months of age, in a state of renal insufficiency and uncontrolled seizures.

Laboratory studies. There was glomerular dysfunction with elevated blood urea nitrogen and creatine, hypertension and proteinuria, tubular dysfunction with metabolic acidosis, aminoaciduria, glucosuria and phosphaturia, hepatic dysfunction with hyperbilirubinemia $(5 \mathrm{mg} / \mathrm{dl}$ total, and $3.8 \mathrm{mg} / \mathrm{dl}$ conjugated bilirubin), and elevated SGPT (95 I.U.). Plasma neutral lipids were increased (total cholestrol $360 \mathrm{mg} / \mathrm{dl}$, esterified cholesterol 270 $\mathrm{mg} / \mathrm{dl}$, triglycerides $402 \mathrm{mg} / \mathrm{dl}$ ), phospholipids and lipoproteins were normal.

A diabetic glucose tolerance test without ketonuria was found. Cerebral spinal fluid protein was normal. The EEG showed a generalized low voltage activity. Ophthalmologic examination showed a tapetoretinal degeneration with pigmentary changes.

Audiometry showed a bilateral neurosensory hearing defect.

Autopsy. The macroscopic examination showed an unusual orange appearance of the liver, heart, and intestine and to a lesser degree of the other viscera. The heart weighed $250 \mathrm{~g}$ with atheromatosis of the endocardium, thoracic aorta and coronary vessels.
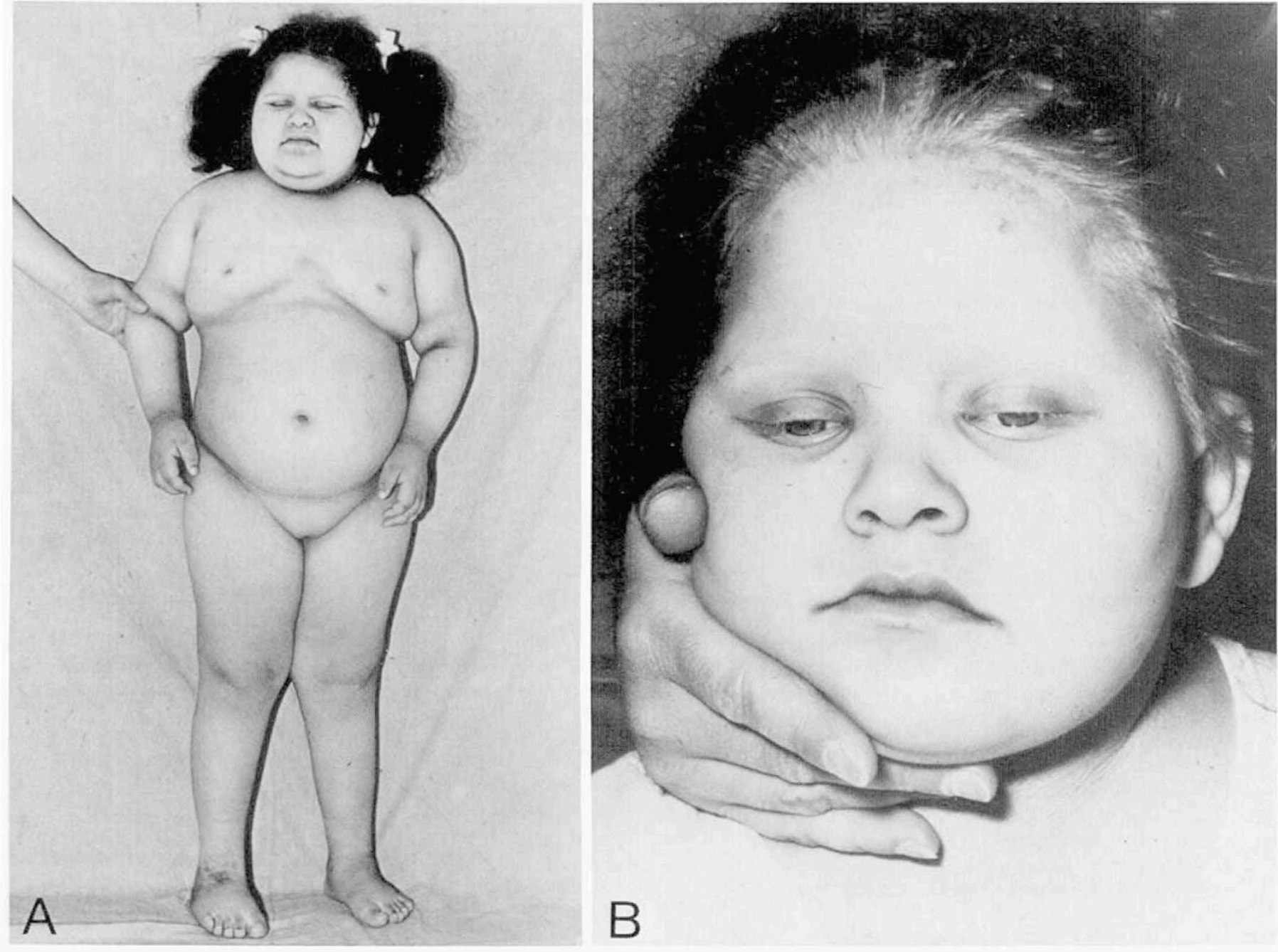

Fig. 1. (A) General appearance of the patient and $(B)$ Moon face. Note the acanthosis nigricans near the hairline and the depigmentation of the hair roots. 
The liver weighed $1850 \mathrm{~g}$ and spleen $250 \mathrm{~g}$. Kidneys were small (left $42 \mathrm{~g}$ and right $52 \mathrm{~g}$ ). The small intestine mucosa had an orange color with thick, flattened yellow villi.

\section{RESULTS}

Histochemistry. All hepatocytes contained lipid droplets (Fig. 2 ). The vacuoles were of variable size and did not usually displace the nuclei. In frozen sections all cells stained intensely with neutral lipid stains (Oil-Red O, Sudan III, and Sudan Black). The Schultz stain for cholesterol or its esters was negative. The periodic acidSchiff stain was positive in small scattered aggregates. Sudanophilic droplets were found in spleen histiocytes, heart muscle fibers, lung alveolar histiocytes and interstitial tissue, and cells of the muscularis mucosa from the proximal parts of the small intestine and terminal ileum. The skin had a thickened parakeratotic stratum corneum with acanthosis. Some dermal cells stained for neutral lipids. Kidney glomeruli were markedly hyalinized with thickening of the basal membrane (Fig. 3A). Kidney tubules presented various degrees of atrophy and cystic dilation with interstitial periglomerular and peritubular fibrosis and marked arteriolar sclerosis (Fig. 3B). In frozen sections, residual tubular cells and interstitial histiocytes were stained for neutral lipids. The ultrastructural examination of a kidney biopsy showed thickening and coalescence of the glomerular basal membrane. These findings were interpreted as an endstage interstitial nephritis with arteriolar and arterial nephrosclerosis, compatible with the juvenile nephronophthisis. In the nervous system, there were focal losses and

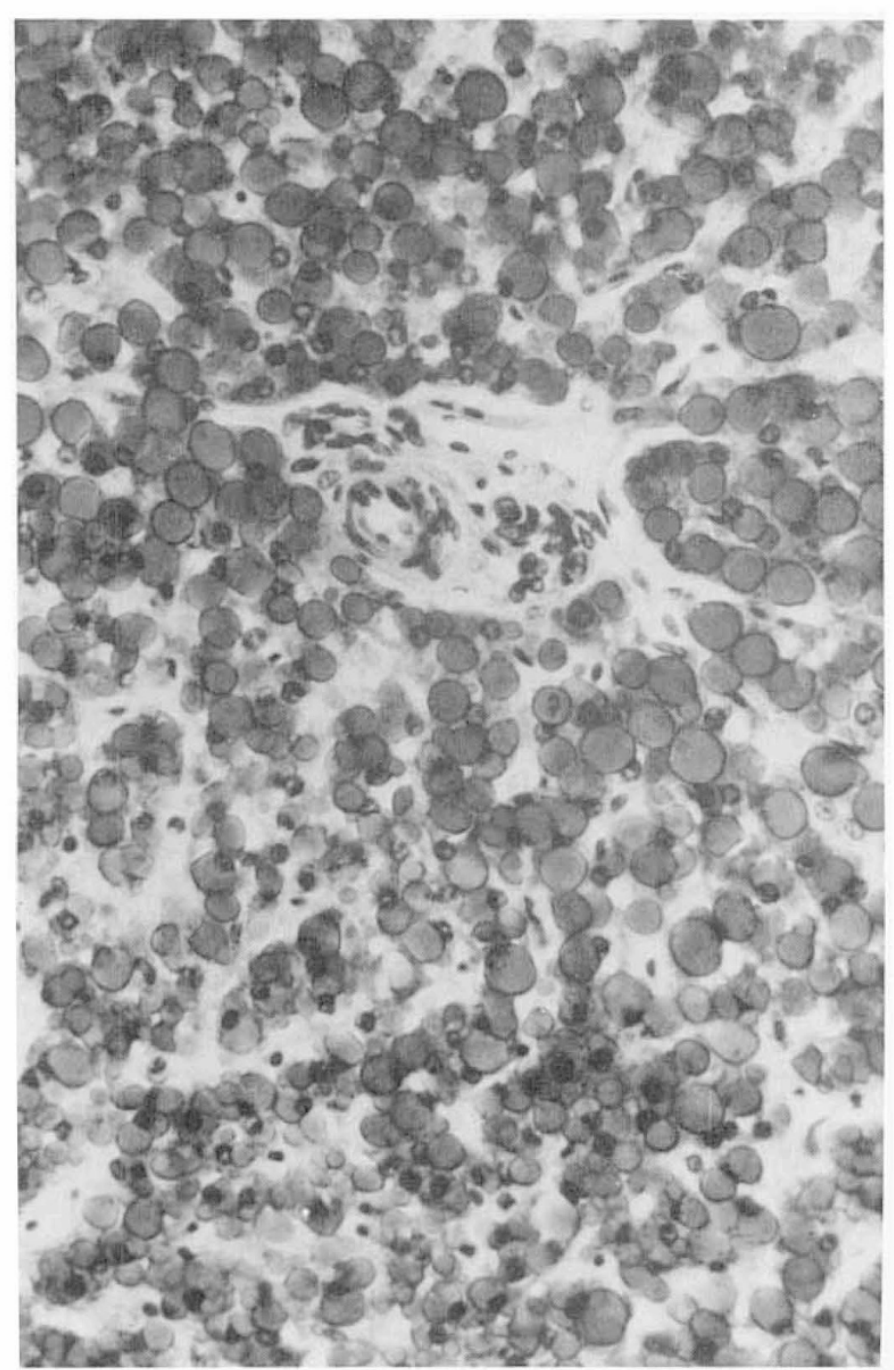

Fig. 2. Liver biopsy. Hepatocytes are filled with large lipid droplets. Oil-Red $\mathrm{O}, \times 100$. lipid storage in cortical neurons and transsynaptic degeneration of the optic pathways.

Lipid composition. The patient's liver contained increased total lipids (3-fold), cholesterol esters (5-fold), and triacylglycerol (8fold), whereas total phospholipids were decreased by $50 \%$ (Table 1). The brain had a normal lipid concentration and composition (data not shown). Thin layer chromatography of brain lipids showed slightly elevated triacylglycerol; cholesterol esters were estimated to represent about $15 \%$ of the free cholesterol, whereas they were barely detectable in controls. In Wolman's disease livers, triacylglycerol was increased (5-fold) as well as cholesterol esters (25-fold) with wide variations from case to case; phospholipids were decreased by $50 \%$.

Cirrhotic livers contained an average 3-4-fold increase in triacylglycerol and cholesterol esters. Phospholipid composition remained normal in all pathologic specimens. No more than trace amounts of lysobisphosphatidic acid were identified.

Lipase activities. The data on patient's samples were all expressed as $\%$ of the control values (Table 2). MU-oleate lipase activity was within normal limits in the cirrhotic livers. It was markedly deficient in the Wolman's and our patient's livers. In our patient's brain, however, this activity was not deficient. Trioleylglycerol and tripalmitylglycerol lipase activities in cirrhosis had an average one-third of the activity of the control livers with wide variations from case to case ranging from $7-87 \%$ of the control mean. These activities were markedly reduced in livers from Wolman's and from our patient within the range found for MU-oleate lipase. In our patient's brain trioleylglycerol lipase varied from $14-60 \%$ of the controls and tripalmitylglycerol lipase activity varied from $14-25 \%$ of the controls. Oleylcholesterol lipase activity was reduced to $20 \%$ of the controls in the only two cirrhotic livers tested. This was in the range also found for the trioleylglycerol and tripalmitylglycerol lipase from these two specimens. Oleylcholesterol lipase was undetectable in livers from our patient's and one Wolman's case. This activity was also reduced at $12-33 \%$ in our patient's brain.

\section{DISCUSSION}

There is a considerable disparity among patients with an oculocerebrohepatorenal syndrome. Tapetoretinal degeneration (24, 39,30 ) and chronic tubulointerstitial nephropathy (Senior Syndrome) have been reported in over 20 patients. Some of those, like our case, presented hepatomegaly, progressive psychomotor deterioration, seizures, deafness, obesity, diabetes mellitus, and ichthyosis. Several were siblings and some were products of consinguineous marriages, supporting an autosomal recessive inheritance. Comparable clinical presentations have been reported (6, $13,25,26)$. The nature of the defect in Senior syndrome (30), Alstrom's syndrome (tapetoretinal degeneration, deafness, obesity, diabetes mellitus and acanthosis nigricans) (13), hepatic fibrosis and nephronophthisis (9) and other apparently related disorders (27) remains undetermined.

The deficient acid lipase activity in our patient explains the generalized triacylglycerol accumulation. TGSD and CESD represent the two extremes in the phenotypic spectrum of acid lipase deficiency. In Wolman's disease both cholesterol esters and triacylglycerols are increased in variable proportion from case to case. It would be tempting to correlate the more benign course with the extent of cholesteryl ester storage, CESD representing the more severe and TGSD the more benign phenotype. Our present case does not support this hypothesis because cholesterol esters were not markedly elevated.

Our patient presented with a generalized neutral lipid storage disorder, which was prominent in the liver and mild in most other tissues, especially the kidney. In our patient's liver, lipid composition was similar to Wolman's cases except for a lower free and esterified cholesterol content. It was also similar to cirrhotic livers except for higher triacylglycerol and lesser phospholipid content.

The demonstration of a severe acid lipase deficiency indicated that we were dealing with a new variant of Wolman's disease. Hepatic steatosis is a nonspecific manifestation of a variety of 

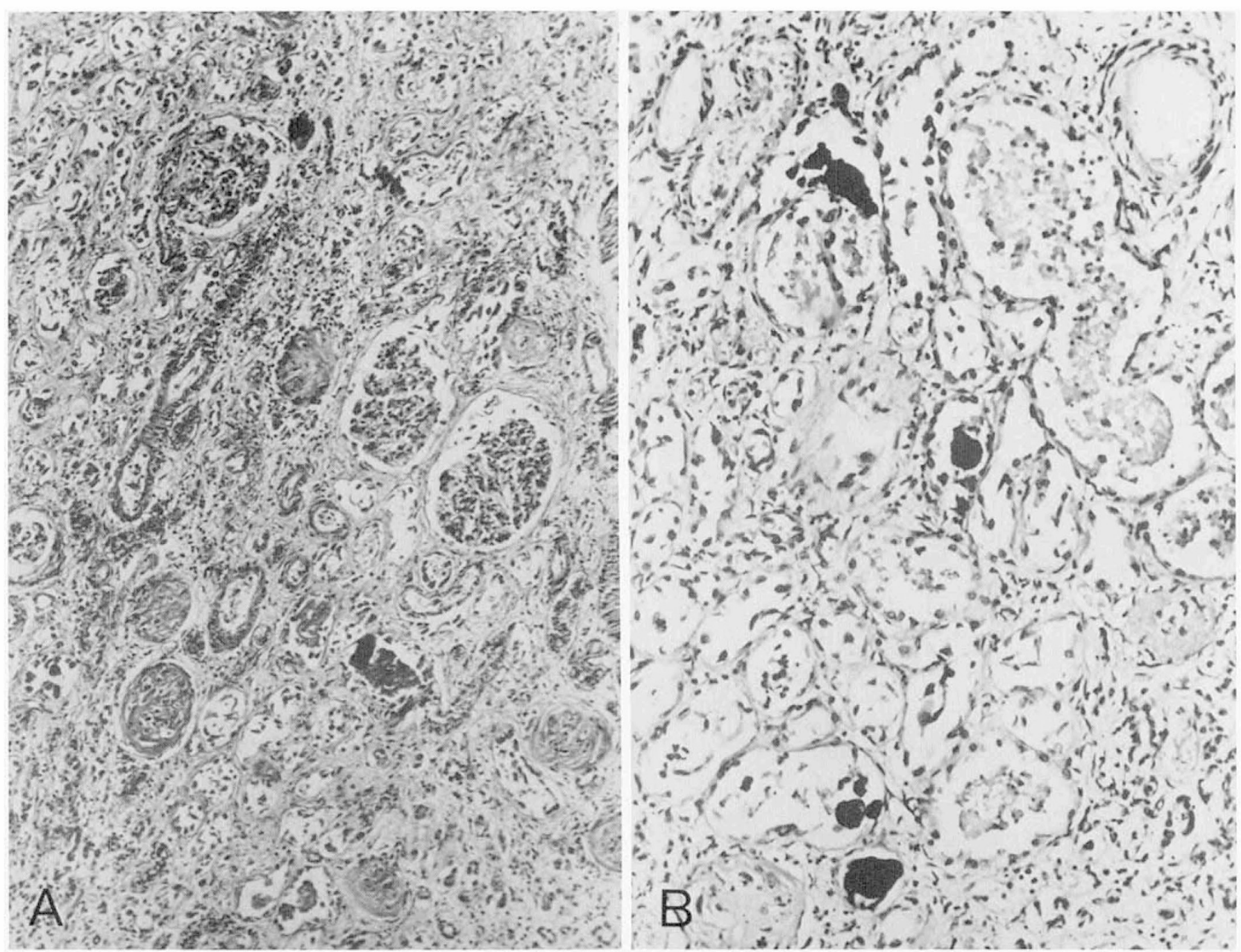

Fig. 3. (A) Kidney biopsy. Glomerular hyalinization with thickening of the basal membrane. Hematoxylin and eosin, $\times 160$. (B) Kidney biopsy, showing tubular atrophy and peritubular fibrosis. Hematoxylin and eosin, $\times 400$.

Table 1. Lipid composition (liver)

\begin{tabular}{lcccc}
\hline & Patient $^{1}$ & Wolman $^{2}$ & Cirrhosis $^{2}$ & Controls $^{2}$ \\
\hline Total lipids & 55.3 & $45.4 \pm 6.2(7)$ & $30.8 \pm 13.4(8)$ & $17.7 \pm 7.0(14)$ \\
Free cholesterol & 0.4 & $0.9 \pm 0.5(4)$ & $0.4 \pm 0.1(3)$ & $0.4 \pm 0.3(9)$ \\
Cholesterol esters & 2.8 & $12.3 \pm 6.7(5)$ & $1.9 \pm 1.1(7)$ & $0.5 \pm 0.2(8)$ \\
Triacylglycerol & 37.8 & $22.8 \pm 15.3(6)$ & $15.5 \pm 13.0(7)$ & $4.6 \pm 5.8(9)$ \\
Total phospholipids & 3.2 & $2.94 \pm 0.87(5)$ & $5.5 \pm 1.0(8)$ & $6.9 \pm 1.4(14)$ \\
\hline
\end{tabular}

${ }^{1}$ Data expressed as $\mathrm{mg} / 100 \mathrm{mg}$ of dry weight.

${ }^{2}$ Mean \pm S.D. (number of specimens).

Table 2. Acid lipase

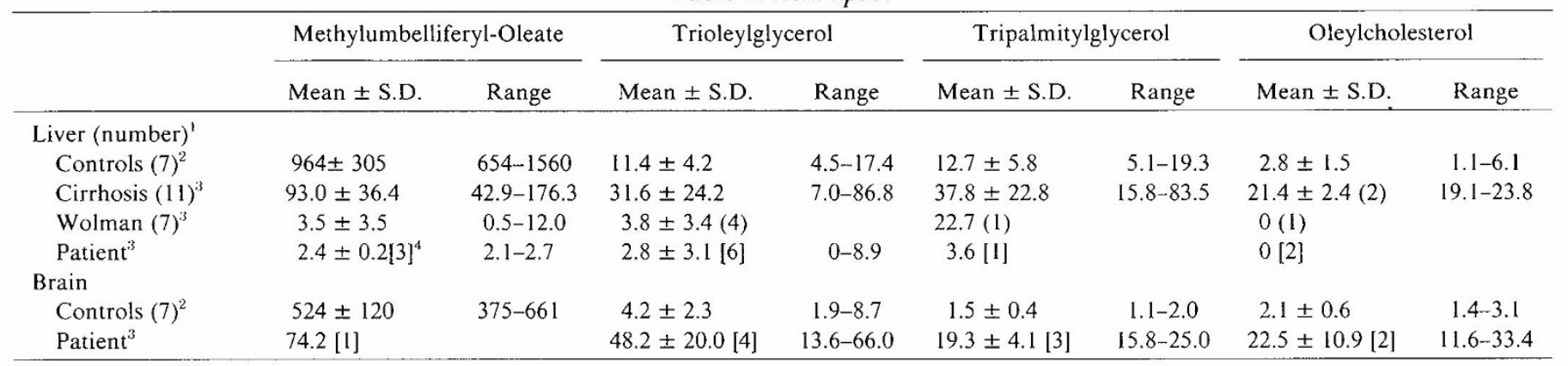

${ }^{1}$ ( ), number of specimens.

${ }^{2}$ Controls values expressed as nmoles $/ \mathrm{h} / \mathrm{mg}$ protein.

${ }^{3}$ Pathologic values expressed as \% of activity in simultaneously run controls.

${ }^{4}[$ ], number of experiments. 
liver insults. Only a minority of cases result from a genetic hydrolase deficiency. Our findings that our patient was deficient in lipase activity against a variety of natural and artificial lipid substrates raised the question whether this could be an apparent deficiency due to the competition between the exogenous substrate and the enormous quantity of endogenous substrate accumulated in the tissue. Alcoholic cirrhotic livers were chosen as easily available controls to clarify this point. The MU-oleate lipase activity was equally deficient in livers from our patient and cases of Wolman's disease, whereas it was not affected in cirrhotic livers. Using several natural neutral lipid substrates, livers from our patient and Wolman's cases were equally deficient whereas there was a wide variation in cirrhotic livers with the lowest values overlapping with Wolman's cases and the higher ones being normal. This indicated either competition with the endogenous substrate or ethanol-induced inhibition of the acid lipase. A small brain fragment of the patient provided an opportunity to study lipase activities in a tissue devoid from massive storage. Brain lipase activities were actually different compared to the liver. They were normal against the artificial substrate and reduced to about one-third of controls against natural substrates; therefore, our patient had a generalized deficiency in lipase activity against natural substrates with a variable expression in brain and liver. Detailed studies of these different lipase activities need to be conducted in different organs from the different variants of Wolman's disease before the significance of these results can be evaluated.

Another approach to study the effect of endogenous substrate on lipase activities was to use acetone powders and butanol extracts. Experiments with cirrhotic livers indicated that endogenous lipids were actually indispensable for testing lipase activities against exogenous substrates (see "Materials and Methods"). The availability of Wolman's tissues being quite limited, we were not able to explore this further.

Highly purified lysosomal lipase from rat liver was shown to require a phospholipid activator and to exhibit abnormal kinetics $(16,33)$. The liver enzyme was inhibited by $2 \mathrm{M}$ ethanol (33), which may be the basis for our findings in alcoholic cirrhosis. Ethanol induced an accumulation of triacylglycerol (32) and cholesterol esters $(17,32)$, and a concomitant reduction in cholesterol esterase activity in rat liver (32). Human liver cholesterol esterase in contradistinction was stimulated by $2.0-4.0 \%$ ethanol $(\mathrm{v} / \mathrm{v})(34)$. The irregular kinetics of the interaction of enzymes with lipid micelles have been discussed in detail (10-12). The enzyme preparation may contain different amounts of activator phospholipids (33) and, in pathologic specimens, increased amounts of natural substrates or products may introduce another variable. Our patient's brain had only limited neutral lipid storage as shown by histochemistry and lipid analysis. This could be expected from the sizable acid lipase activities against natural substrates. In Wolman's disease, too, there is little lipid storage in the brain (14), but acid lipase activity has not been adequately investigated. The lack of brain lipid storage in presence of an hydrolase deficiency is also known in infantile Gaucher's disease (23) and Niemann-Pick disease type B (35). The neuronal losses might result from vascular impairment or a putative toxic factor such as that proposed for Gaucher's disease (24). Triacylglycerol and cholesterol esters are at most minor components of neurons and myelin and the traces found in normal brain probably mostly derive from non-neural elements included in the specimen, such as capillaries, meninges, and macrophages. Tissues either not apparently affected or abnormal but not involved by the storage process need to be carefully studied in lysosomal storage disorders, searching for causes of functional cellular impairment that might be more damaging than the storage itself.

Lipid storage, for example, was not prominent in our patient's kidney. A similar inconspicuous storage was reported in the biopsy from the original case from Senior's Syndrome. Because the study of patients with an oculocerebrohepatorenal syndrome has focused on the kidney, the occurrence of the lipid storage may have been overlooked or not searched for in other organs. In the future it would be important to screen such patients for acid lipase deficiency.

\section{REFERENCES AND NOTES}

1. Aubert-Tulkens, G. and Van Hoof, F.: Acid lipase deficiency: clinical and biochemical heterogeneity. Acta Paediatrt. Belg., 32: 239 (1979).

2. Den Tandt, W. R., Philippart, M., Nakatani, S., and Durand, P.: Triglyceride and acid lipase deficiency in triglyceride storage disease, a possible variant of Wolman's disease. Pediatr. Res., 7: 346 (1973).

3. Durand, P., Bugiani, O., Palladini, G., Borrone, C., Della Cella, G., and Siliato F.: Nephropathie tubulo-interstitielle chronique, degenerescence tapeto-retinienne et lipidose generalisee. Arch. Franc. Ped.. 28: 915 (1971).

4. Fletcher, M. J.: A colorimetric method for estimating serum triglycerides. Clin. Chim. Acta, 22: 393 (1968)

5. Folch, J., Lees, M., and Sloane Stanley G. H.: A simple method for the isolation and purification of total lipides from animal tissues. J. Biol. Chem., 226: 497 (1957)

6. Fontaine, J. L., Boulesteix, J., Saraux, H., Lasfargues, G., Grebet, P., N'GhiemMinh, D., Dhermy, P., Roy, C., and Laplane, R.: Nephropathie tubulointerstitielle de l'enfant avec degenerescence tapeto-retinienne (syndrome de Senior). Arch Franc. pediat., 27: 459 (1970).

7. Fredrickson, D. S. and Ferrans, V. J.: Acid cholesteryl ester hydrolase deficiency (Wolman's disease and Cholesteryl ester storage disease). In: J. B. Wyngaarden, and D. S. Fredrickson: The Metabolic Basis of Inherited Disease. pp 670-687, 4th ED., (McGraw-Hill, New York, New York 1978).

8. Freeman, C. P. and West D.: Complete separation of lipid classes on a single thin-layer plate. J. Lipid Res., 7: 324 (1966).

9. Freycon, M. T., Ravussin, J. J., Gilly, J., and Freycon. R.: Nephrite tubulointerstitielle avec fibrose hepatique. Pediatrie, 32: 685 (1977).

10. Gatt, S. and Bartfai. T.: Rate equations and stimulation curves for enzymatic reactions which utilize lipids as substrates. I. Interaction of enzymes with monomers and micelles of soluble, amphiphilic lipids. Biochim. Biophys. Acta, 488: 1 (1977).

11. Gatt, S. and Bartfai, T.: Rate equations and stimulation curves for enzymatic reactions which utilize lipids as substrates. II. Effect of adsorption of the substrates or enzyme on the steady-state kinetics. Biochim. Biophys. Acta, 488 : 13 (1977).

12. Gatt, S.: Inhibitors of enzymes of phospholipid and sphingolipid metabolism. In: R. M. Hochster, M. Kates and J. H. Quastel: Metabolic Inhibitors. A comprehensive Treatise. Vol. 4, pp 349-387, (Academic Press, New York, London, 1973).

13. Goldstein, J.L. Fialkow, P. J, Fraser, G. R and Stricker, G. E. Alstrom's syndrome: A heretofore unrecognized cause of hereditary nephropathy: 4th Intern. Congress of Human Genetics. Excerpta Medica, 233: 80 (1971)

14. Guazzi, G. C., Martin, J. J., Philippart, M., Roels, H., Hooft, C., Van der Eecken H., Delbeke, M. J., and Vrints. L.: Wolman's disease. Distribution and significance of the central nervous system lesions. Path. Europ., 3: 266 (1968).

15. Kaplan, A.: A Simple Radioactive Assay for Triglyceride Lipase. Anal. Biochim. 33: $218(1970)$

16. Kariya, M. and Kaplan, A.: Effects of acidic phospholipids, nucleotides, and heparin on the activity of lipase from rat liver liver lysosomes. J. Lipid Res. 14: 243 (1973)

17. Lefevre, A. F., DeCarli, L. M., and Lieber, C. S.: Effects of ethanol on cholesterol and bile acid metabolism. J. Lipid Res., 13: 48 (1972).

18. Lowden, J. A.: The quantitative determination of cholesterol in brain lipid extracts using gas-liquid chromatography. J. Chromatogr., 27: 246 (1967).

19. Lowry, O. H., Rosebrough, N. J., Farr, A. L., and Randall, R. J.: Protein measurement with the Folin phenol reagent. J. Biol. Chem., 193: 265 (1951).

20. Patrick, A. E. and Lake, B. D.: Deficiency of an acid lipase in Wolman's disease. Nature, 222: 1067 (I969)

21. Peremans, J., De Graef, P. J., Strubbe, G., and De Block, G.: Familial metabolic disorder with fatty metamorphosis of the viscera. J. Pediatr., 69: 1108 (1966).

22. Philippart, M., Den Tandt, W., Borrone, $C_{\text {., }}$ and Durand, P.: Retinal renal dysplasia and encephalopathy in a patient with triglyceride storage disease. Acta. Genet. Med. Gemellol., 23: 201 (1974).

23. Philippart $\mathbf{M}$. and Menkes $\mathbf{J}$. H.: Isolation and characterization of the principal cerebral glycolipids in the infantile and adult forms of Gaucher's disease. In S. M. Aronson and B. W. Volk: Inborn Disorders of Sphingolipid Metabolism. pp 389-400, (Pergamon Press, Oxford, New York, 1966).

24. Philippart, M.: Clinical and biochemical pathophysiology of ataxia in the sphingolipidoses. Adv. Neurol. 21: 131 (1978).

25. Popvic-Rolovic. M., Calic-Perisic, N., Bunjevacki, G., and Negovanovic, D. Juvenile nephronophtisis associated with retinal pigmentary dystrophy, cerebellar ataxia and skeletal abnormalities. Arch. Dis. child., 51: 801 (1976).

26. Proesmans, W., Van Damme, B., and Macken, J.: Nephronophthisis and tapetoretinal degeneration associated with liver fibrosis. Clin. Nephrol., 3: 160 (1975).

27. Rayner, A., Lampert, R., and Rennert, O. M.: Familial ichthyosis, dwarfism, mental retardation and renal disease. J. Pediat., 92: 766 (1978).

28. Rouser, G., Fleischer, S., and Yamamoto, A.: Two-Dimensional Thin-Layer Chromatographic Separation of Polar Lipids and Determination of Phospholipids by Phosphorus Analysis of Spots. Lipids, 5: 494 (1970).

29. Schimke, R. N.: Hereditary renal-retinal dysplasia. Ann. Int. Med., 70: 735 (1969). 
30. Senior, B.: Familial renal-retinal dystrophy. Am. J. Dis. Child., 125: 442 (1969). 31. Sloan, H. R. and Fredrickson, D. S.: Enzyme Deficiency in Cholesteryl Ester Storage Disease. J. Clin. Invest., 5I: 1923 (1972).

32. Takeuchi, N., Ito, M., and Yamamura, Y.: Esterification of cholesterol and hydrolysis of cholesteryl ester in alcohol induced fatty liver of rats. Lipids, 9 : 353 (1974).

33. Teng, M. H. and Kaplan, A.: Purification and properties of rat liver lysosomal lipase. J. Biol. Chem., 249: 1064 (1974).

34. Warner, T. G., Tennant, L. L., Veath. M. L., and O'Brien, J. S.: An improved method for the isolation and assay of the acid lipase from human liver. Biochem. Biophys. Acta., 572: 201 (1974).

35. Wenger, D. A., Kudoh. T., Sattler, M., Palmieri, M., and Yudkoff, M.: NiemannPick Disease Type B: Prenatal Diagnosis and Enzymatic and Chemical Studies on Fetal Brain and Liver. Am. J. Hum. Genet., 33: 337 (1981).

36. Young, E. P. and Patrick, A. D.: Deficiency of Acid Esterase Activity in Wolman's Disease. Arch. Dis. Child., 45: 664 (1970).

37. New England Nuclear. Boston, Massachusetts.

38. Sigma Chemical Company. St. Louis, Missouri.

39. Berthold Radioactive Scanner equipped with a Dot Printer, Wurzburg, West Germany.

40. The authors thank Kathy Kampf for her expert technical assistance

41. Requests for reprints should be addressed to: Dr. Michel Philippart, UCLA Mental Retardation Center, 760 Westwood Plaza, Los Angeles 90024 (USA).

42. This research was supported in part by USPHS Grant HD-05615.

43. Received for publication Febraury 8, 1982

44. Accepted for publication June 10, 1982.

Copyright (c) 1982 International Pediatric Research Foundation. Inc 